\title{
Variability in sensitivity among different host origin- Macrophomina phaseolina isolates to azoxystrobin fungicide
}

\author{
ABHIJEET GHATAK*, CHANDA KUSHWAHA, RAMESH NATH GUPTA ${ }^{1}$, KUNAL PRATAP SINGH \\ AND MOHAMMAD ANSAR \\ Department of Plant Pathology, Bihar Agricultural University, Sabour, BHAGALPUR (BIHAR) INDIA \\ ${ }^{1}$ Pulses Research Center, MOKAMA (BIHAR) INDIA \\ ${ }^{2}$ Jute Research Station, KATIHAR (BIHAR) INDIA
}

\section{ARITCLE INFO \\ Received : 15.12 .2016 \\ Revised : 24.02 .2017 \\ Accepted : 01.03.2017}

\section{KEY WORDS :}

Azoxystrobin, Charcoal rot, Fungicide, Macrophomina phaseolina

*Corresponding author:

Email : ghatak11@gmail.com

\begin{abstract}
The charcoal rot fungus, Macrophomina phaseolina, was isolated from chickpea, pigeonpea, groundnut and jute root tissues collected from Bihar and Uttar Pradesh. Variability in isolates was recognized i.e. feathery growth for pigeonpea and jute isolates, and restricted growth for chickpea and soybean isolates. The sensitivity of $M$. phaseolina from the four hosts was tested for azoxystrobin, a respiration inhibitor (QoI group) fungicide. The minimum inhibitory concentration was lower (10 ppm) for isolates with restricted growth and higher (between 100 and $150 \mathrm{ppm}$ ) for isolates with feathery growth. Concentrations of this fungicide pose significant impact $(\mathrm{P}<0.01)$ on time requirement for growth of isolate. We found strong effectiveness of azoxystrobin to inhibit the growth of slow-growing population of M. phaseolina. Moreover, this fungicide can also exploit for the fast-growing population of M. phaseolina but more time will be required, to act on such isolates, for better result of azoxystrobin. Our results indicate that the response of different isolates varied to concentrations of azoxystrobin; this could be interpreted that the fungicidal application may be performed only after the quantitative estimation of the prevailing population type in the field as because various populations of M. phaseolina may be available in an area. Therefore, our results advocate for judicious use of fungicide (azoxystrobin) application, which ultimate restrict the hazardous impact on soil health.
\end{abstract}

How to view point the article : Ghatak, Abhijeet, Kushwaha, Chanda, Gupta, Ramesh Nath, Singh, Kunal Pratap and Ansar, Mohammad (2017). Variability in sensitivity among different host origin-Macrophomina phaseolina isolates to azoxystrobin fungicide.. Internat. J. Plant Protec., 10(1) : 26-33, DOI : 10.15740/HAS/IJPP/10.1/26-33. 